\title{
X-Shaped ZIF-8 for Immobilization Rhizomucor miehei Lipase via Encapsulation and Its Application toward Biodiesel Production
}

\author{
Miaad Adnan ${ }^{1,2}$, Kai $\mathrm{Li}^{1}$, $\mathrm{Li} \mathrm{Xu}{ }^{1}$ and Yunjun Yan ${ }^{1, *}$ \\ 1 Key Laboratory of Molecular Biophysics of the Ministry of Education, College of Life Science and \\ Technology, Huazhong University of Science and Technology, Wuhan 430074, China; \\ miaadadnan14@gmail.com (M.A.); D201577434@hust.edu.cn (K.L.); xuli@hust.edu.cn (L.X.) \\ 2 Ministry of Science and Technology, Baghdad 10001, Iraq \\ * Correspondence: yanyunjun@mail.hust.edu.cn; Tel.: +86-27-8779-2213
}

Received: 25 January 2018; Accepted: 26 February 2018; Published: 28 February 2018

\begin{abstract}
This study presents a one-step encapsulation method for synthesizing X-shaped zeolitic imidazolate frameworks (ZIF-8) and immobilizing Rhizomucor miehei lipase (RML). We proved that the morphological structure of ZIF- 8 had changed after immobilization with enhanced characterization using a field-emission scanning electron microscope, an energy-dispersive spectrometer, a transmission electron microscope, a Fourier transform infrared spectrometer, and powder X-ray diffraction. The surface area and pore size of the carrier were investigated before and after immobilization using Brunauer-Emmett-Teller and Barrett-Joyner-Halenda methods, respectively. RML@ZIF-8 exhibited high recovery activity of up to $2632 \%$, representing a 26 -fold increase in its free lipase. Encapsulated RML was used for biodiesel production from soybean oil in an isooctane system with a conversion yield of $95.6 \%$ under optimum conditions. The resulting reusability of the immobilized enzyme indicated no substantial decline in the conversion yield, which remained at $84.7 \%$ of the initial activity after 10 cycles. The stability and high performance of the immobilized enzyme are attributed to the harmony between RML and ZIF-8 based on the easy synthesis of ZIF-8 and the short time required to immobilize RML.
\end{abstract}

Keywords: X-shape ZIF-8; Rhizomucor miehei lipase (RML); encapsulation technique; biodiesel yield; soybean oil

\section{Introduction}

The depletion of fossil fuel resources and the environmental impacts of fossil fuel use are the main motives for investigating and developing renewable fuel sources. The term biodiesel implies a fuel that is biodegradable, and such fuels are being increasingly used in compression-combustion engines [1]. Biodiesel consists of oxoalkyl esters that include ethyl and methyl esters that originate from animal fats or vegetable oils as renewable feedstock [2]. However, the applicability of the chemical processes used to create biodiesel has been restricted due to substantial energy requirements, challenges in retrieving catalyzers, and various environmental barriers [3]. Enzymatic methods, including lipase catalysis, are more advantageous than chemical processes due to their lower energy consumption, easier product retrieval, environmentally friendly means, and adaptability to a broad range of crude substances, particularly those with large free fatty acid content [4]. Despite the multiple advantages of lipases, the high price of enzyme catalysts is a significant barrier in biodiesel manufacturing. Immobilization is a possible solution to this problem, because immobilized lipases are repeatable and tolerate a wide range of $\mathrm{pH}$ values, temperatures, and organic solvents and more stable than the free counterparts [5].

In-depth studies have explored immobilization enzymes and their applications to various fields. The literature describes conventional methods used in immobilization, adsorption, covalent bond 
cross-linking, and entrapping [6,7]. The adsorption technique is easy to complete, but the bonding of enzymes is frequently weak, resulting in the leaching of biocatalysts [8]. Conversely, covalent techniques prevent leaching, but the processes are lengthy and require several chemical steps that lead to the loss of enzyme activity [9]. The entrapment technique has attracted considerable interest because of its numerous advantages, including its speed, stability, simple treatment process, low cost, and requirement of mild conditions [10]. Macario et al. [11] investigated the sol-gel for entrapped lipase, obtaining the highest yield of fatty acid methyl esters at $77 \%$ and retaining $60 \%$ of the original activity after five batches. For biodiesel synthesis, lipase from Pseudomonas cepacia was encapsulated into hydrophobic sol-gel, yielding nearly $67 \%$ [4]. Calcium alginates were used as substrates for providing beads; the obtained biocatalysts were reused for four cycles with minimal leakage [12]. These materials that use gel structures for entrapment, such as calcium alginate or sol-gel, suffer from mass transfer limitation; thus, the biocatalyst performance is slightly restricted, which is another disadvantage in addition to the leaching of enzymes and loss of activity $[13,14]$. To overcome this problem, coordinated matrices of carriers are needed with a pore size that allows the flow of substrates and other materials, but is sufficiently small to prevent the rinsing of encapsulated enzymes.

To this end, we have been investigating the potential of metal-organic frameworks (MOFs). MOFs are hybrid materials with both organic and inorganic components that acts a host and protective shield for enzymes subjected to harsh environmental conditions [15].

The zeolitic imidazolate framework (ZIF-8), an MOF subdivision, is a novel type of microporous material formed by the coordination between zinc $\left(\mathrm{Zn}^{2+}\right)$ ions and 2-methylimidazole. It is the branch of the ZIF subclass of MOFs that has attracted significant research attention due to its high porosity, tunable surface properties, negligible cytotoxicity, exceptional thermal and chemical stability, and ease of synthesis under mild biocompatible conditions $[16,17]$. These properties allow ZIF- 8 to be used for a variety of applications, such as adsorption, separation, [18,19], gas storage [20], drug delivery [21], and catalysis [22].

In the present work, we used X-shaped ZIF-8 as a carrier to immobilize Rhizomucor miehei lipase (RML) via the encapsulation method in a single step from synthesis and immobilization in an aqueous solution. We also investigated the optimum conditions for immobilizing lipases. Several specific characteristics of the encapsulated RML@ZIF-8 and its morphological properties were studied to prove the ability of the lipase to directly regulate the morphology of ZIF- 8 and ensure successful immobilization. Eventually, experiments were performed with the encapsulated lipase by stimulating transesterification in biodiesel production from soybean oil.

\section{Results and Discussion}

\subsection{Synthesis and Characterization of ZIF-8 and Lipase@ZIF-8}

The lipase was entrapped within ZIF-8 using the encapsulation method (Figure 1), dried in a vacuum dryer, and characterized by scanning electron microscope (SEM), the morphology of ZIF-8 changed after RML encapsulation, as shown in Figure 2a,b. The same morphology was identified by TEM (Figure 2c,d), but it did not match the morphology obtained by Cui et al. [23], who reported that the shape of ZIF-8 did not change with the macromolecule protein (lipase). EDS analysis demonstrated differences between ZIF-8 and RML@ZIF-8 (Figure 2e,f). The immobilized lipase consisted of sodium (Na) due to the presence of RML. However, we did not find Na in ZIF-8, confirming the success of the immobilization. 

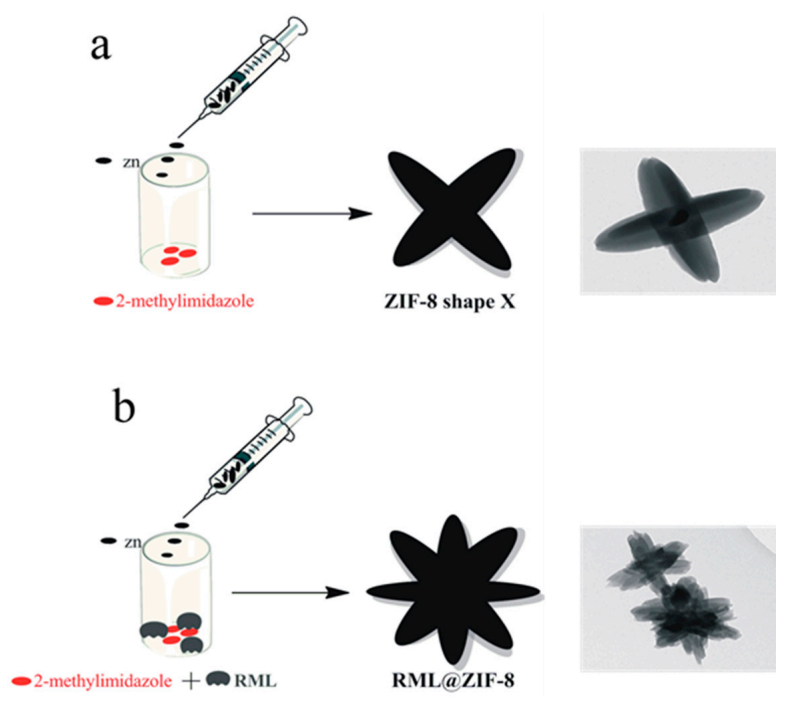

Figure 1. Schematic illustration of (a) the synthesis of zeolitic imidazolate frameworks (ZIF-8) and (b) the immobilization of Rhizomucor miehei lipase (RML)@ZIF-8.

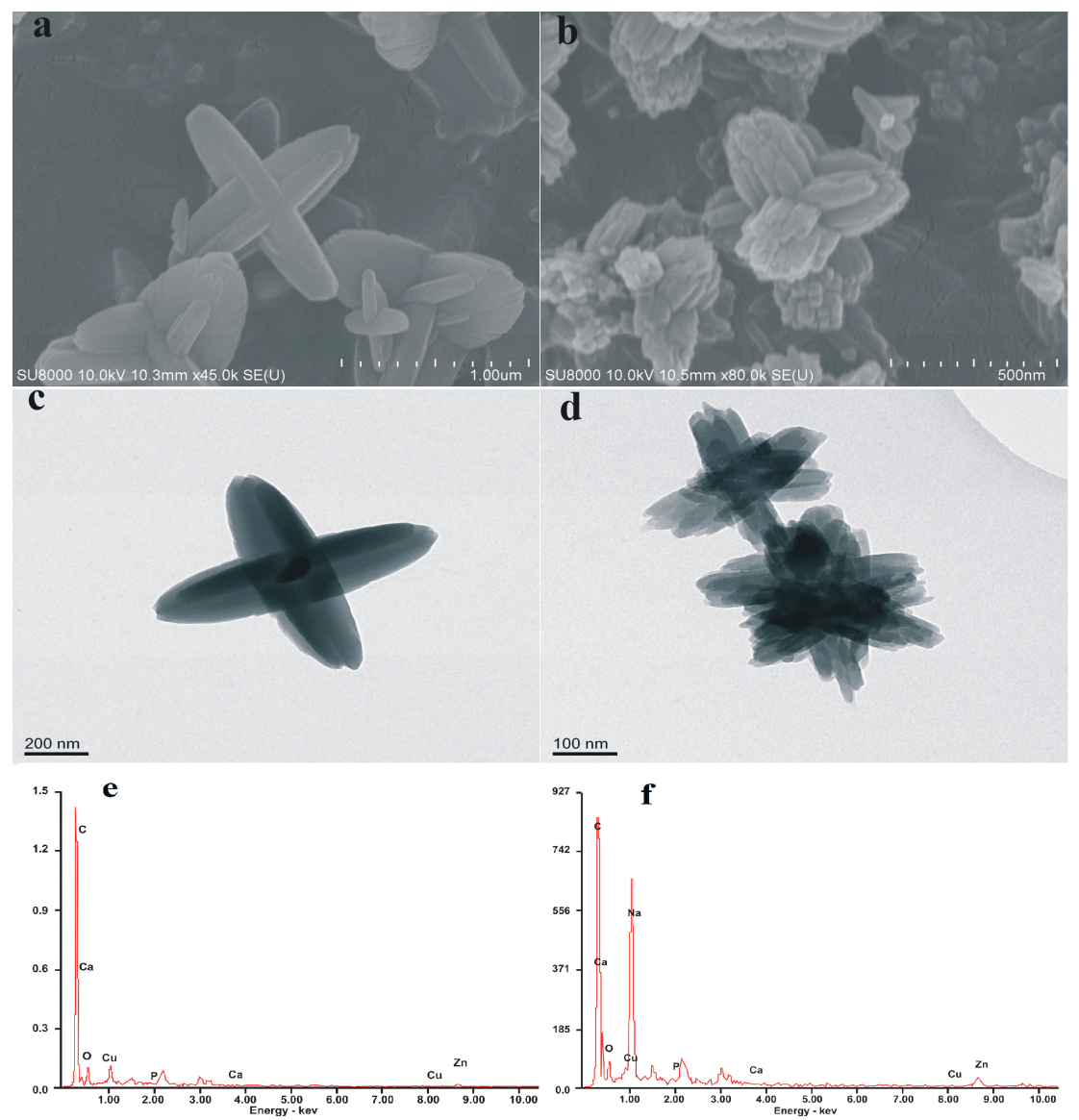

Figure 2. SEM images (a) ZIF-8 and (b) ZIF-8@RML; TEM images of (c) ZIF-8 and (d) ZIF-8@RML; EDS patterns of (e) ZIF-8 and (f) RML@ZIF-8.

Figure 3 presents additional evidence for RML encapsulation in ZIF-8. The FTIR spectra exhibited ZIF-8, RML@ZIF-8, and absolute RML. A notable characteristic peak of Zn-N stretched at $434 \mathrm{~cm}^{-1}$. The strong bending vibrations at 756 and $1424 \mathrm{~cm}^{-1}$ were due to the Hmim ring. Simultaneously, 
the feeble peaks at $2922-3200 \mathrm{~cm}^{-1}$ were due to the aliphatic and aromatic stretching of the C-H bond of Hmim [24]. The aforementioned bands in the spectrum included ZIF-8 and RML@ZIF-8. The spectrum (RML) displayed characteristic bands of the free RML protein. Two bands were observed at 1640-1660 and $3370-3380 \mathrm{~cm}^{-1}$, which align with the amide I band of the enzyme, corresponding to $\mathrm{C}=\mathrm{O}$ and $\mathrm{N}-\mathrm{H}$ stretching, respectively. After the immobilization of RML in ZIF-8, the same characteristic peaks of RML were retained.

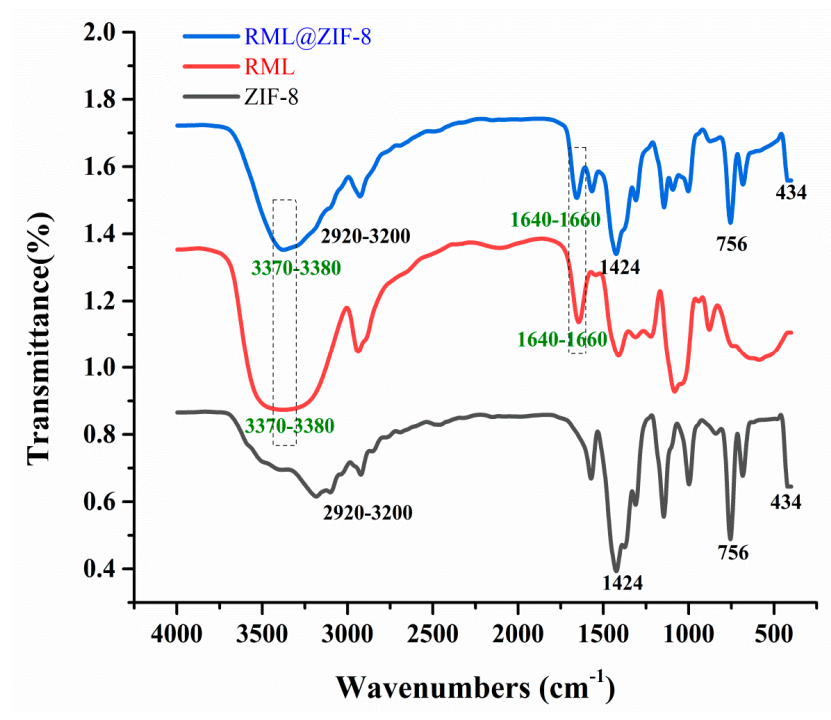

Figure 3. Fourier transform infrared (FT-IR) spectra of samples of ZIF-8, RML, and ZIF-8@RML.

Powder X-ray diffraction (PXRD) further confirmed our findings by demonstrating the differences in the peak intensities of ZIF-8 and lipase@ZIF-8. The main summits denoted the increase in intensity for pure ZIF-8 at $2 \theta=10.98^{\circ}, 15.11^{\circ}, 17.04^{\circ}, 18.01^{\circ}, 21.76^{\circ}, 27.78^{\circ}$, and $29.05^{\circ}$, which corresponded to the $1833,1840,2800,3710,1388,1504$, and 2245 plates of the crystal face structure. In contrast, the intensity of lipase@ZIF-8 decreased due to the diminished distance between the atomic layers in the crystalline material and the decrease in crystallinity of RML@ZIF-8 after modification [25,26]. This result shows that the modification of the morphological properties of ZIF-8 resulted from the encapsulation of biomacromolecules (RML) (Figure 4).

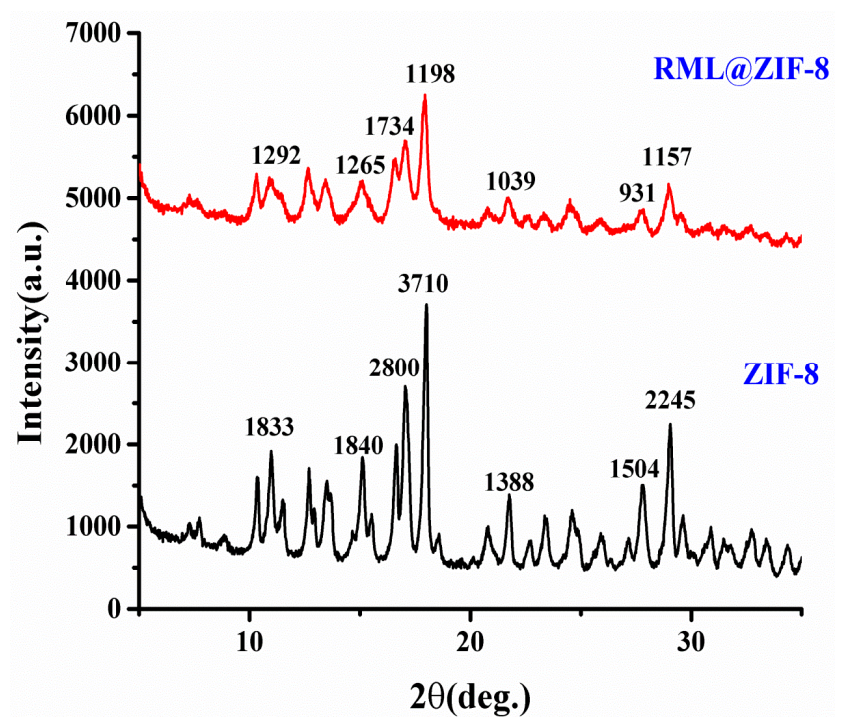

Figure 4. PXRD patterns of ZIF-8 of ZIF-8@RML. 
For ZIF-8 and RML@ZIF-8, Figure 5 shows the $\mathrm{N}_{2}$ adsorption-desorption isotherm test results, which were between Types I and IV, correlating to the International Union of Pure and Applied Chemistry (IUPAC), which suggests that this nanocomposite contains micro- and mesopores due to the gas adsorption at low relative pressure and increased uptake at pressures higher than $0.6 \mathrm{P} / \mathrm{P0}$ [27]. The BET-based specific surface area for ZIF-8 before lipase immobilization was $697.51 \mathrm{~m}^{2} / \mathrm{g}$, but this value decreased to $593.36 \mathrm{~m}^{2} / \mathrm{g}$ after immobilization. The average pore diameter of RML@ZIF-8 was $4.65 \mathrm{~nm}$ after immobilization and $9.67 \mathrm{~nm}$ before immobilization. This is a $5.11 \mathrm{~nm}$ reduction in diameter. These results were due to the role of the enzyme in modulating the morphological properties of ZIF-8 during the immobilization process. In this case, RML occupied some of the pores and destroyed other pores, creating new pores with different sizes and unusual shapes. Consequently, the surface area and diameter of the pores reduced.
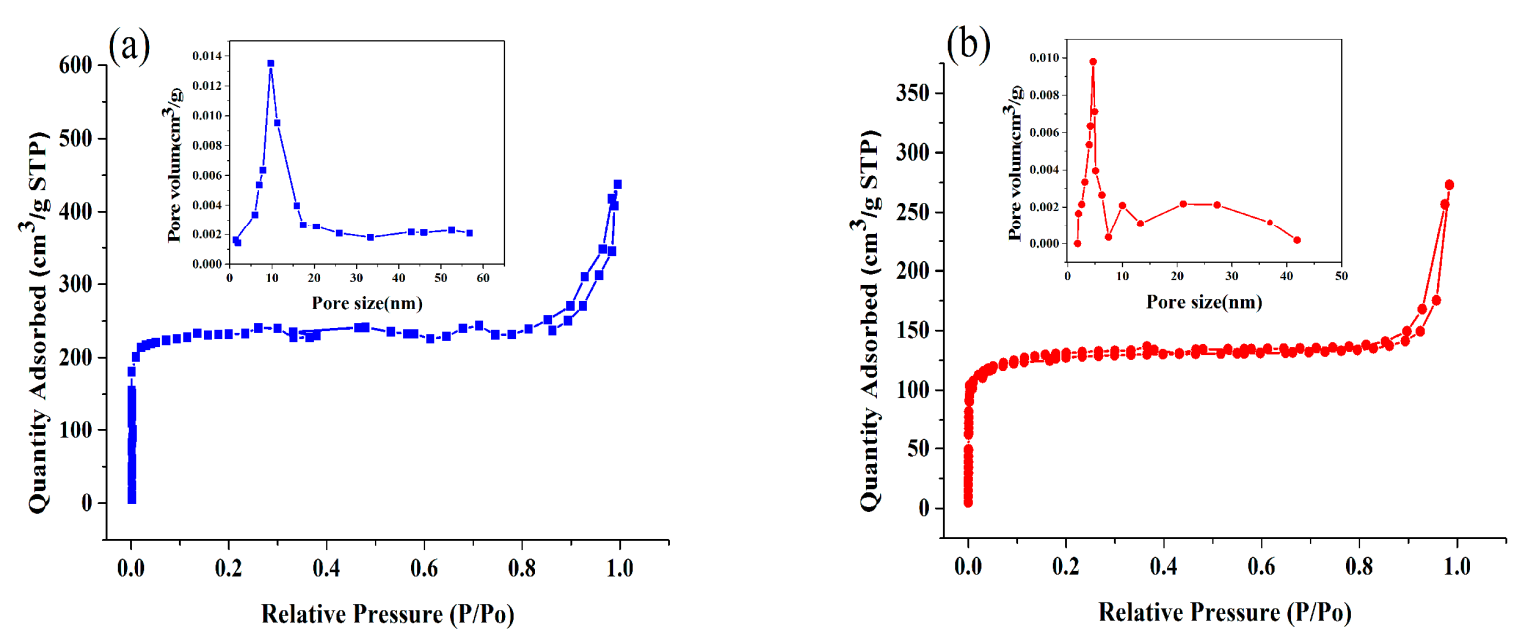

Figure 5. Nitrogen adsorption-desorption isotherms and pore size distributions (insert figures) for (a) ZIF-8 and (b) RML@ZIF-8.

\subsection{Impacts of Immobilization Parameters}

During lipase immobilization, we observed the effects of enzyme loading, encapsulation time, and immobilization temperature on the efficiency of immobilization and activity recovery. For lipase loading, the amount of lipase ranged from 15 to $27 \mathrm{mg}$ and was increased by $2 \mathrm{mg}$ after each run. Maximum activity recovery was $2426 \%$ when RML loading was $25 \mathrm{mg}$, whereas the immobilization efficiency exhibited a consistent decline whenever loading increased (Figure 6a). Therefore, we chose $25 \mathrm{mg}$ as the suitable lipase amount for the immobilization of RML. A large quantity of lipase loading can reduce activity recovery, as the enzyme particles interred in the inner pore of ZIF- 8 cannot be reached by the substrate [28].

Duration time did not significantly affect the efficiency of immobilization. The activity recovery increased with increasing encapsulation time, reaching the highest value of $2528 \%$ at $20 \mathrm{~min}$ and then decreasing when the encapsulation time exceeded $20 \mathrm{~min}$. Consequently, $20 \mathrm{~min}$ was chosen as the best encapsulation period (Figure $6 b$ ). The enzyme activity in the aqueous phase decreased as encapsulation time increased [29].

For the immobilization temperature, immobilization efficiency increased gradually. Activity recovery increased despite the elevated temperature, reaching a maximum value of $2632 \%$ at $30{ }^{\circ} \mathrm{C}$. Thereafter, activity recovery began to decline due to the thermal inactivation of the lipase (Figure 6c). Thus, $30^{\circ} \mathrm{C}$ was chosen as the most suitable immobilization temperature. 
(a)

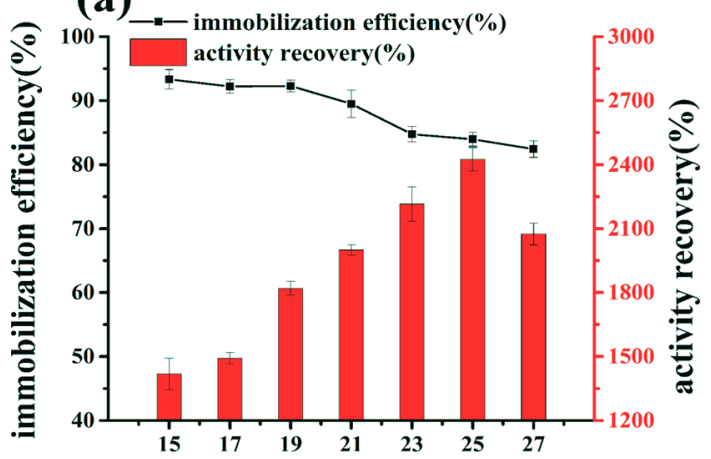

Amount of lipase (mg) (b)

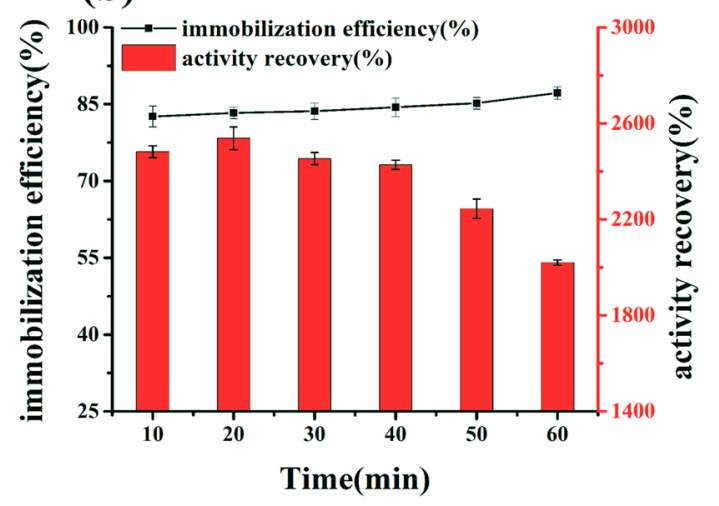

(c)

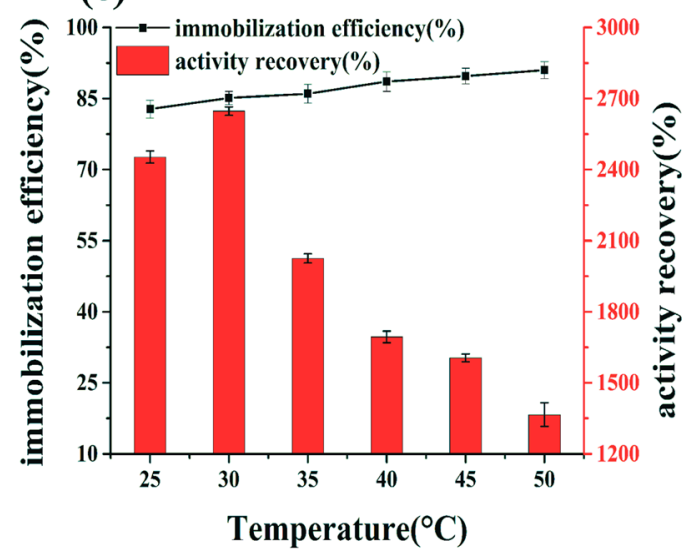

Figure 6. Impacts of three variables on the immobilization efficiency and activity recovery of the enzyme. (a) Amounts of lipase, (b) encapsulation time and (c) reaction temperature.

Under these optimal conditions, enzyme loading, encapsulation time, and immobilization temperature led to a 26 -fold increase in the activity recovery of the enzyme relative to the free enzyme. This result is attributed to the features of the carrier and to the immobilization method and unique characteristics of the lipase. To improve the activity and stability of the immobilized enzyme caused by the complicated process, the following factors were considered. The first factor is related to the immobilization method. The encapsulation method was found to be better than other conventional methods because it protects the enzyme upon encapsulation and prevents direct contact between the enzyme and the substrate, which can influence enzyme activity. The other methods used for immobilization occasionally couple the active site of the enzyme with the substrate, leading to an expected loss in enzyme activity due to direct contact [30,31]. Second, immobilization carriers, and particularly ZIF-8, can significantly affect enzyme activity by creating microenvironments that are suitable for enzyme catalysis through ZIF-8 for a limited time in mild biocompatible conditions that allow for the preservation of enzymatic activity [32,33]. In addition, MOF biomimetic mineralization is aided by the attraction of biomacromolecules (lipase) to imidazole, which is a component that emerges from intermolecular hydrogen bonding and hydrophobic interactions. Simultaneously, RML affects the morphology, crystal dimension, and crystallinity when it is encapsulated within the porous crystal, leading to the formation of different holes that firmly envelope the lipase [34]. Finally, the active catalytic center of the lipase is closed by the mobile element called the "lid" configuration, which regulates the passage of substrates to active enzymatic sites. The secondary structure related to RML can be altered by the conformation of lipase@ZIF- 8 . The lid opens to the substrate for a long period, which causes an increase in lipase activity due to the ease of access [35]. 


\subsection{Influence of Transesterification Parameters on the Biodiesel Yield}

Many previous reports explored the effects of kinetic parameters on transesterification reactions in biodiesel production. We conducted a string of investigations to identify the ideal conditions to production (FAAE) using the biocatalysis of lipase@ZIF-8 with soybean oil.

As shown in Figure 7a, the biodiesel product considerably increased to $84.7 \%$ with the addition of $20 \%$ isooctane to the reaction system. Above $20 \%$ isooctane, the biodiesel yield gradually decreased. An explanation for this phenomenon is that the residual amino acids in the lid react with the isooctane molecules, so the immobilized enzyme remains in the open conformation, reaching higher catalytic activity [36]. We ascribe the decrease in biodiesel yield to the ethanol and the by-product, glycerol, exhibiting poor solubility in isooctane when the concentration and deposit of ethanol and glycerol layering on RML occur with an isooctane concentration above 20\% [37].

Water is fundamental to the reaction mixture in ester production because it retains and enhances enzyme activity in organic solvents [38]. Furthermore, water significantly influences the reaction equilibrium. The transesterification reaction involves aqueous and organic phases that enable the lipase to work at water-oil interfaces; thus, performance is appreciably influenced by the interfacial region [39]. As shown in Figure 7b, RML@ZIF activity significantly increased when 3\% water was added to the reaction mixture, therefore proving that activating the enzyme requires a small amount of moisture content. The highest biodiesel yield of $87.1 \%$ was obtained with $9 \mathrm{wt} \%$ water. The conversion yield decreased to $83.1 \%, 81.5 \%$, and $72.8 \%$ yield with a water content of $12 \%, 15 \%$, and $18 \%$, respectively. Nevertheless, the moisture concentration in a transesterification reaction mixture can positively or negatively affect the lipase catalytic activity. Excess moisture in the reaction mixture provides the lipase with additional flexibility and can lead to undesirable reactions, such as hydrolysis. For example, the highest catalytic activity in the transesterification of commercial Novozym 435 lipase was achieved without adding water to the batch system [40]. Thus, the best moisturizing content is the lowest value in hydrolysis and the highest enzyme activity for the transesterification reaction, depending on the oil of the feedstock, the organic solvent, lipase type, and the immobilized carrier [28].

The catalytic activity of each enzyme at the optimum temperature directly influences the rate and velocity of the reaction. Hence, the impact of temperature on enzymatic reactions should not be neglected. According to Figure 7c, the maximum conversion yield of RML@ZIF-8 transesterification was $88.8 \%$ at a temperature of $45^{\circ} \mathrm{C}$. A further increase in temperature to $55^{\circ} \mathrm{C}$ induced a notable drop in biodiesel product. As reported, the optimal temperature for enzymatic transesterification results from the interaction between the transesterification rate and operational stability of the biocatalyst [41,42].

Alcohols have two roles in transesterification reactions. First, the surplus of alcohols in transesterification reactions increases the reaction rate and drives the high yield of FAEEs [43]. Second, a high concentration of alcohol negatively affects enzymes, which typically become unstable in alcohols, such as ethanol and methanol, enabling the deactivation of RML@ZIF-8 through its contact with insoluble ethanol that exists in a reaction system and results from decreases in ethyl ester production [44]. Accordingly, we determined the optimum volume of ethanol added to the system that causes the least harm to the lipase and leads to an increase in maximal conversion value (Figure $7 \mathrm{~d}$ ). The highest conversion yield for biodiesel was $91.2 \%$ at a molar ratio of 1:4, declining gradually when the molar ratio increased from 1:5 to 1:6.

Yan et al. [45] reported that an equivalent of alcohols higher than $1 / 2 \mathrm{M}$ added to the mixture at onset interplay disrupt the enzyme activity. To prevent the inactivation of the enzyme caused by alcohol, we applied a stepwise addition of EtOH to the system. Thus, the interval time between alcohol addition and the reaction positively affected the reaction system. Fan et al. [46] obtained a 93.1\% biodiesel yield when they used a three-step approach with a time interval of $10 \mathrm{~h}$. Therefore, we studied the effects of the interval time of ethanol addition on biodiesel product. We improved biodiesel yield from 73.8 to $92.3 \%$ when we increased the interval time from 4 to $8 \mathrm{~h}$ (Figure 7e). Although the interval time was extended to $12 \mathrm{~h}$, this level of transmutation did not significantly increase biodiesel yield 
due to the dynamic equilibrium in the reaction components. Therefore, the optimal biodiesel yield required an $8 \mathrm{~h}$ interval. Based on that, $8 \mathrm{~h}$ were regarded as the best interval at which ethanol is added, and a maximum biodiesel yield of $92.3 \%$ was obtained within a $24 \mathrm{~h}$ reaction time.

To reduce the cost of biodiesel production and obtain maximum yield, we optimized the measure of immobilized RML added to the reaction mixture. Biodiesel product increased as the quantity of immobilized enzyme was increased from 4 to $14 \mathrm{wt} \%$, and the highest output of $95.6 \%$ was found at $8 \mathrm{wt} \%$ (Figure $7 \mathrm{f}$ ). No considerable improvement in the conversion yield was observed when the lipase dosage was increased from 8 to $14 \%$. Therefore, $8 \mathrm{wt} \%$ RML@ZIF- 8 was considered the best dosage.

(a)
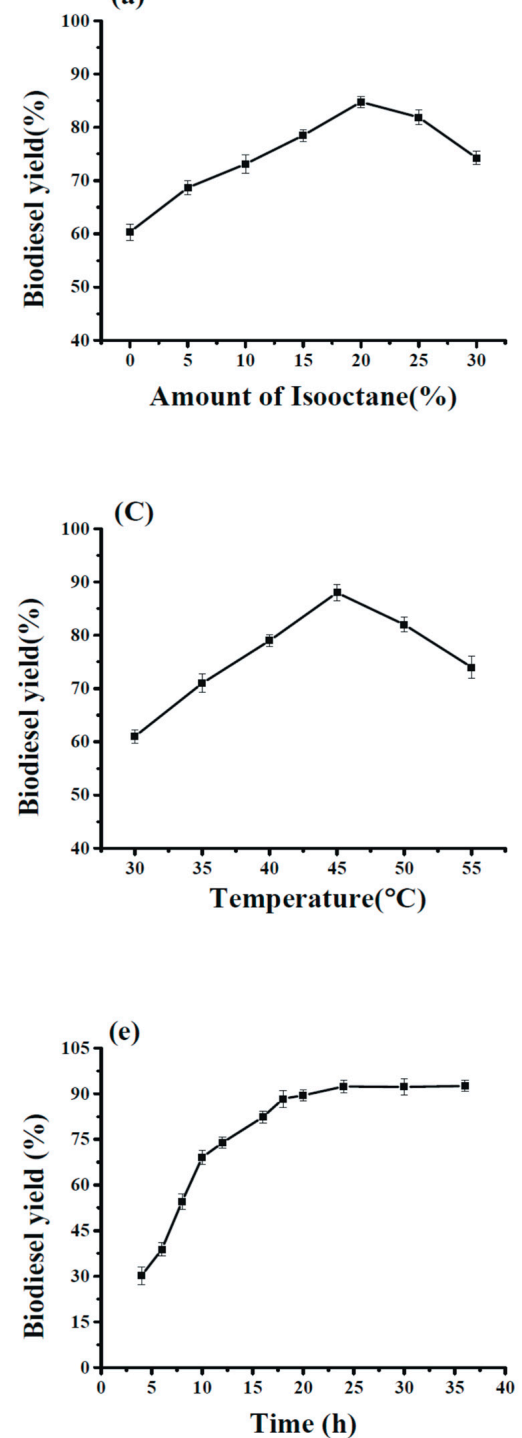

(b)

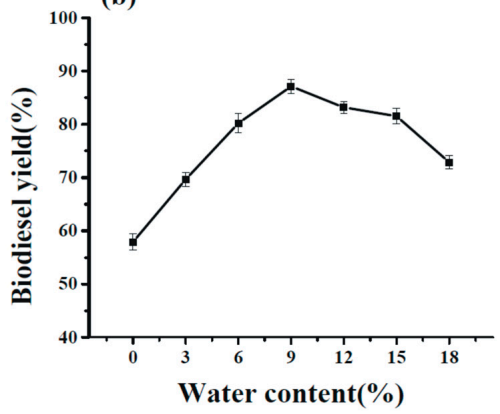

(d)
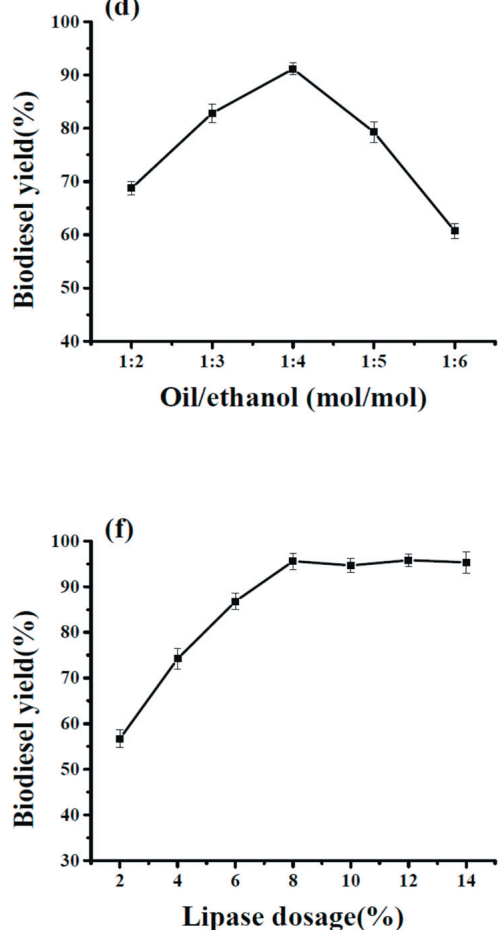

Figure 7. Impacts of reaction parameters on biodiesel production catalyzed by RML@ZIF-8. (a) The amount of isooctane; (b) Water content; (c) Reaction temperature; (d) Molar ratio oil to ethanol; (e) Reaction time; (f) The dosage of lipase.

\subsection{Reusability of the Immobilized RML@ZIF-8}

The purpose of using immobilize lipase in industrial applications is to achieve reusability, reducing the cost of the process. The reusability of RML@ZIF- 8 in an isooctane medium was investigated, and the results are presented in Figure 8. We noted that the encapsulation of ZIF-8 to RML maintained an 
$84.7 \%$ yield after a continuous run of 10 cycles. The immobilized RML in the X-shaped ZIF- 8 carrier had good operational stability. The lipase immobilized by the encapsulation method was more stable than it was under physical adsorption and was different from the covalent bonding that used a complex and time-consuming mechanism to connect the enzyme to the carrier. The proposed method specifically uses a relatively simple design and procedure. The decrease in biodiesel yield production with an increasing number of cycles was attributed to the excess ethanol and the glycerol by-product being adsorbed onto the surface of RML@ZIF-8. The poor solubility of these alcohols in feedstock oil decreases the biodiesel yield, which results from the gradual inactivation of the enzyme. Breaking the carrier apart by mechanical force results in a continuous reaction and leads to lipase leakage, reducing the effect of the immobilized lipase.

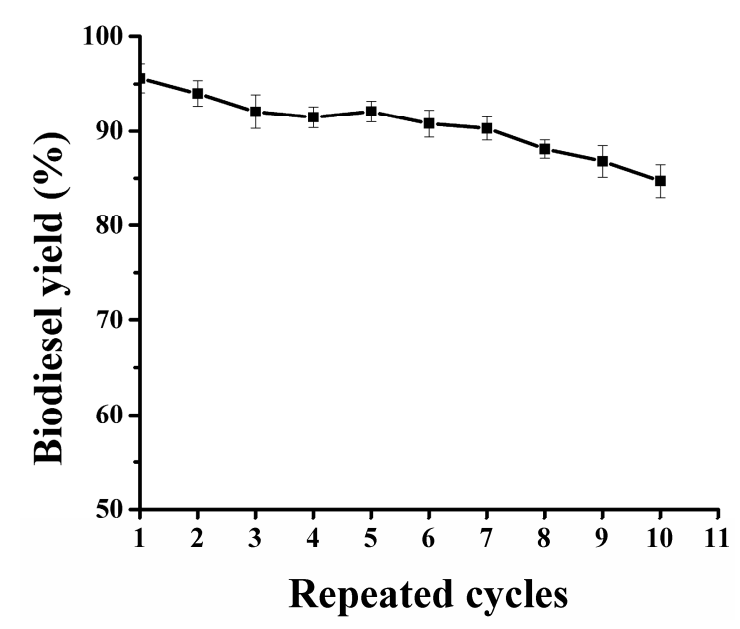

Figure 8. Reuse of RML@ZIF-8 for biodiesel production.

\section{Materials and Methods}

\subsection{Materials}

Lipase from Rhizomucor miehei (RML) was purchased from Sigma Aldrich (Copenhagen, Denmark). 2-Methylimidazole (HMeIM) and fatty acid methyl and ethyl ester standards were purchased from Aladdin Industrial Corporation (Shanghai, China). Bovine serum albumin (BSA) was procured from Shenshi Chemical Industry (Wuhan, China). Soybean oil with nearly $99 \%$ purity was brought from local markets. Other reagents of analytical grade were purchased from Sinopharm Chemical Reagent Co., Ltd. (Shanghai, China). These reagents included $\mathrm{Zn}\left(\mathrm{NO}_{3}\right)_{2} \cdot 6 \mathrm{H}_{2} \mathrm{O}$, lauric acid, acetone, 1-dodecanol, ethanol, isooctane, hexane, phenolphthalein, and sodium hydroxide $(\mathrm{NaOH})$. They were used without any further purification. For all the experiments, purified water was used in the water refining system, with a resistance exceeding $18.2 \mathrm{M} \Omega \mathrm{cm}$.

\subsection{Lipase Immobilization}

Zif-8 encapsulated lipases were prepared according to a modified method [23]. Zn (NO3) ${ }_{2}(0.148 \mathrm{~g}$, $0.5 \mathrm{M}$ ) had been disbanding in $1 \mathrm{~mL}$ deionized (DI) water and dripped through a syringe into mixture solution of $25 \mathrm{mg}$ of lipase and 2-methylimidazole $(0.656 \mathrm{~g}, 0.8 \mathrm{M}, 10 \mathrm{~mL})$ under stirring at $200 \mathrm{rpm}$ at $30^{\circ} \mathrm{C}$ for $20 \mathrm{~min}$. The nanoparticles that formed were gathered by centrifuging at $8000 \mathrm{rpm}$ for $6 \mathrm{~min}$ and washed twice with DI water to remove excess unbound lipase. RML@ZIF-8 was vacuum dried and stored at $4{ }^{\circ} \mathrm{C}$ until further use. The remaining protein content in the supernatant was measured to determine the amount of immobilized enzyme using the Bradford protein assay with bovine serum albumin (BSA) as the standard protein. Within the immobilization procedure, the impacts of enzyme loading, period immobilization, and temperature on specific activity, immobilization efficiency, and lipase activity recovery were examined. 


\subsection{Measurement Activity for Immobilization Enzyme}

The activity of RML@ZIF-8 and free lipases was examined with the esterification process previously explained [47]. A specific amount of the free and immobilized enzyme was added to $10 \mathrm{~mL}$ of a combination containing 1-dodecanol $(0.2 \mathrm{M})$ and lauric acid $(0.2 \mathrm{M})$ in isooctane with the addition of $0.01 \mathrm{~mL}$ water. The reactions occurred at $40{ }^{\circ} \mathrm{C}$ for $30 \mathrm{~min}$ with persistent agitation at $200 \mathrm{rpm}$. Afterward, the reactions were stopped by adding $1 \mathrm{~mL}$ of the samples to $5 \mathrm{~mL}$ of the stop solution consisting of acetone-ethanol $1: 1, \mathrm{v} / \mathrm{v} . \mathrm{NaOH}(0.05 \mathrm{M})$ was used in a titration to determine residual acid in the sample. Phenolphthalein solution $(0.05 \%, \mathrm{w} / \mathrm{v})$ was used as a $\mathrm{pH}$ indicator. One unit of RML activity (U) was expressed as the quantity of lipase required to liberate $1 \mu \mathrm{mol}$ of lauric acid per $1 \mathrm{~min}$ under the assay conditions. The specific activity (U/g protein), activity recovery $(\%)$, and immobilization efficiency (\%) were determined using Equations (1)-(3) [29].

$$
\begin{gathered}
\text { Specific activity }(\mathrm{U} / \mathrm{g} \text { protein })=\frac{\text { initial activity }}{\text { protein content of immobilized lipase }} \\
\text { Immobilization efficiency }(\%)=\frac{\text { immobilized protein }}{\text { total loading protein }} \times 100 \% \\
\text { Activity recovery }(\%)=\frac{\text { activity of immobilized lipase }}{\text { total activity of free lipase }} \times 100 \%
\end{gathered}
$$

\subsection{Characterization}

The detailed morphological structure was visualized using a field emission-scanning electron microscope (FE-SEM) SU-8010 equipped with a Hitachi energy-dispersive spectrometer (EDS) for elemental analysis. Transmission electron microscopy (TEM) images were obtained with an H-7000FA (Hitachi, Tokyo, Japan). Fourier-transform infrared spectrometer (FT-IR) images were obtained on a Bruker, VERTEX 70 using the KBr pellet system, in the range of $400-4000 \mathrm{~cm}^{-1}$. Powder X-ray diffraction (PXRD) (Empyrean PANanalytical Company, Almelo, The Netherlands) patterns were conducted using copper and potassium radiation $(40 \mathrm{kV}, 40 \mathrm{~mA})$ to study the crystal structures of ZIF-8 and RML@ZIF-8. The nitrogen gas adsorption and desorption isotherms at $77 \mathrm{~K}$ were applied to Micromeritics ASAP 2420 (Norcross, GA, USA). The surface area was measured using the Brunauer-Emmett-Teller (BET) method. Pore size was measured using the Barrett-Joyner-Halenda design.

\subsection{Lipase@ZIF-8 for Biodiesel Production}

Lipase@ZIF-8 was used as a catalyst for real world applications, such as biodiesel production for soybean oil. Transesterification reactions were performed in $50 \mathrm{~mL}$ capped flasks with a shaking speed of $200 \mathrm{rpm}$. The mixed reaction included $2.19 \mathrm{~g}$ soybean oil, RML@ZIF-8 lipase, isooctane, ethanol, and water. Ethanol was added in three steps to avoid its inhibitory influence on the immobilized RML during the same period. The effects of biodiesel production conditions, including isooctane amount, immobilized RML amount, water content, alcohol-to-oil molar ratio, reaction temperature, and reaction duration, were methodically determined. After a specified reaction time, the supernatant was collected through centrifugal separation at $12,000 \mathrm{rpm}$ for $5 \mathrm{~min}$. Thereafter, $10 \mu \mathrm{L}$ supernatant was withdrawn and mixed with $290 \mu \mathrm{L}$ n-hexane and $300 \mu \mathrm{L}$ of $1.0 \mathrm{mg} / \mathrm{mL}$ heptadecanoic acid methyl ester as the interior standard. The mixture was then completely agitated for gas chromatography (GC) to determination biodiesel yield.

\subsection{GC Analysis of Biodiesel Yield}

The fatty acid ethyl esters (FAEEs) content was analyzed via GC using a previously reported method [48]. We used heptadecanoic acid methyl ester as the interior standard for defining biodiesel products. The GC-9790 gas chromatography system included an Agilent HP-INNOWAX capillary 
column (30 $\mathrm{m} \times 0.25$ i.d. $\mathrm{mm} \times 0.25 \mu \mathrm{m}$, Scientific, Folsom, CA, USA). The initial column temperature was $180{ }^{\circ} \mathrm{C}$ and was then increased to $230{ }^{\circ} \mathrm{C}$ at a rate of $3^{\circ} \mathrm{C} / \mathrm{min}$ and maintained at $230{ }^{\circ} \mathrm{C}$ for $3 \mathrm{~min}$. The injector and detector temperatures were fixed at $230{ }^{\circ} \mathrm{C}$ and $280{ }^{\circ} \mathrm{C}$, respectively. The biodiesel yield (\%) was specified as the gross quantity of FAAE content in the diversion oil. The output was computed using Equations (4)-(6) [49,50]:

$$
\begin{gathered}
\text { Weight of FAAE }=\frac{\text { Asample }_{0}}{\text { AinternalWinternal }} \\
f_{0}=\frac{\text { WsampleAinternl }}{\text { WinternalAsample }} \\
\text { Biodiesel yield }(\%)=\frac{W e}{W t} \times 100 \%
\end{gathered}
$$

where $A_{\text {sample }}$ is the peak region of FAAE in specimen, $f_{0}$ is the response agent, $A_{\text {internal }}$ is the peak region of the interior standard, $W_{\text {internal }}$ is the weight $(\mathrm{g})$ of the interior standard, $W_{\text {sample }}$ is the weight (g) of the sample, $W_{e}$ is the experimental value of FAAE tested with GC, and $W_{t}$ is the theoretical value of FAAE.

\section{Conclusions}

We successfully immobilized lipase in X-shaped ZIF-8 for the first time using the encapsulation method within a short time period under mild conditions. In addition, we enhanced the esterification activity 26-fold by optimizing the immobilization conditions. The immobilized RML was applied to catalyze biodiesel production with a high diversion average and excellent operational stabilization. Moreover, the SEM and TEM analyses indicated a change in the morphology of ZIF-8 after immobilizing the lipase. This X-shaped RML@ZIF-8 nanobiocatalyst is promising not only for biofuel production but also for other industrial applications, such as biosensors, the food industry, and biopharmaceuticals.

Acknowledgments: This work was financially supported by the National Natural Science Foundation of China (grant Nos. 31070089, 31170078 and J1103514), the National High Technology Research and Development Program of China (grant Nos. 2013AA065805 and 2014AA093510), the National Natural Science Foundation of Hubei Province (grant No. 2015CFA085), and the Fundamental Research Funds for HUST (grant Nos. 2014NY007, 2017KFYXJJ212, 2017KFXKJC010, 2017KFTSZZ001). The authors thank Chen Hong from Analytical and Testing Centre of HUST for her valuable assistance in XRD, FT-IR, EDS, TEM, and FE-SEM measurement and Li Na from the key laboratory of material chemistry for energy conversion and storage (HUST) for help in BET test. Many thanks are indebted to the Analytical and Testing Center of Huazhong University of Science and Technology for the measurements of water quality.

Author Contributions: Miaad Adnan and Yunjun Yan conceived and designed the experiments; Miaad Adnan and Kai Li performed the experiments and wrote the paper; Li Xu analyzed the data; Miaad Adnan and Yunjun Yan contributed to the revision and proofreading of the manuscript.

Conflicts of Interest: The authors declare no conflict of interest.

\section{References}

1. Guldhe, A.; Singh, B.; Mutanda, T.; Permaul, K.; Bux, F. Advances in synthesis of biodiesel via enzyme catalysis: Novel and sustainable approaches. Renew. Sustain. Energy Rev. 2015, 41, 1447-1464. [CrossRef]

2. Mehrasbi, M.R.; Mohammadi, J.; Peyda, M.; Mohammadi, M. Covalent immobilization of Candida antarctica lipase on core-shell magnetic nanoparticles for production of biodiesel from waste cooking oil. Renew. Energy 2017, 101, 593-602. [CrossRef]

3. Fan, Y.; Wu, G.; Su, F.; Li, K.; Xu, L.; Han, X.; Yan, Y. Lipase oriented-immobilized on dendrimer-coated magnetic multi-walled carbon nanotubes toward catalyzing biodiesel production from waste vegetable oil. Fuel 2016, 178, 172-178. [CrossRef]

4. Zhang, B.; Weng, Y.; Xu, H.; Mao, Z. Enzyme immobilization for biodiesel production. Appl. Microbiol. Biotechnol. 2012, 93, 61-70. [CrossRef] [PubMed] 
5. Abdulla, R.; Ravindra, P. Cross-Linked Lipase in Hybrid Matrix for Biodiesel Production from Crude Jatropha Curcas Oil; Springer: Boston, MA, USA, 2013; pp. 197-202.

6. Garmroodi, M.; Mohammadi, M.; Ramazani, A.; Ashjari, M.; Mohammadi, J.; Sabour, B.; Yousefi, M. Covalent binding of hyper-activated Rhizomucor miehei lipase (RML) on hetero-functionalized siliceous supports. Int. J. Biol. Macromol. 2016, 86, 208-215. [CrossRef] [PubMed]

7. Mohammadi, M.; Ashjari, M.; Dezvarei, S.; Yousefi, M.; Babaki, M.; Mohammadi, J. Rapid and high-density covalent immobilization of Rhizomucor miehei lipase using a multi component reaction: Application in biodiesel production. RSC Adv. 2015, 5, 32698-32705. [CrossRef]

8. Luna, D.; Calero, J.; Sancho, E.D.; Luna, C.; Posadillo, A.; Bautista, F.M.; Romero, A.A.; Berbel, J.; Verdugo, C. Technological challenges for the production of biodiesel in arid lands. J. Arid Environ. 2014, 102, 127-138. [CrossRef]

9. Zubiolo, C.; Santos, R.C.; Carvalho, N.B.; Soares, C.M.; Lima, A.S.; de Aquino Santana, L.C. Encapsulation in a sol-gel matrix of lipase from aspergillus niger obtained by bioconversion of a novel agricultural residue. Bioprocess Biosyst. Eng. 2014, 37, 1781-1788. [CrossRef] [PubMed]

10. Su, F.; Li, G.; Fan, Y.; Yan, Y. Enhanced performance of lipase via microcapsulation and its application in biodiesel preparation. Sci. Rep. 2016, 6, 29670. [CrossRef] [PubMed]

11. Macario, A.; Moliner, M.; Corma, A.; Giordano, G. Increasing stability and productivity of lipase enzyme by encapsulation in a porous organic-inorganic system. Microporous Mesoporous Mater. 2009, 118, 334-340. [CrossRef]

12. Yadav, G.D.; Jadhav, S.R. Synthesis of reusable lipases by immobilization on hexagonal mesoporous silica and encapsulation in calcium alginate: Transesterification in non-aqueous medium. Microporous Mesoporous Mater. 2005, 86, 215-222. [CrossRef]

13. Zhao, Z.Y.; Liu, J.; Hahn, M.; Qiao, S.; Middelberg, A.P.J.; He, L. Encapsulation of lipase in mesoporous silica yolk-shell spheres with enhanced enzyme stability. RSC Adv. 2013, 3, 22008. [CrossRef]

14. Betancor, L.; Luckarift, H.R. Bioinspired enzyme encapsulation for biocatalysis. Trends Biotechnol. 2008, 26, 566-572. [CrossRef] [PubMed]

15. Liang, K.; Coghlan, C.J.; Bell, S.G.; Doonan, C.; Falcaro, P. Enzyme encapsulation in zeolitic imidazolate frameworks: A comparison between controlled co-precipitation and biomimetic mineralisation. Chem. Commun. 2016, 52, 473-476. [CrossRef] [PubMed]

16. Zhang, C.; Dai, Y.; Johnson, J.R.; Karvan, O.; Koros, W.J. High performance zif-8/6fda-dam mixed matrix membrane for propylene/propane separations. J. Membr. Sci. 2012, 389, 34-42. [CrossRef]

17. Yim, C.; Lee, H.; Lee, S.; Jeon, S. One-step immobilization of antibodies on zif-8/fe3o4 hybrid nanoparticles for the immunoassay of staphylococcus aureus. RSC Adv. 2017, 7, 1418-1422. [CrossRef]

18. Khan, N.A.; Jung, B.K.; Hasan, Z.; Jhung, S.H. Adsorption and removal of phthalic acid and diethyl phthalate from water with zeolitic imidazolate and metal-organic frameworks. J. Hazard. Mater. 2015, 282, 194-200. [CrossRef] [PubMed]

19. Lin, K.-Y.A.; Chang, H.-A. Efficient adsorptive removal of humic acid from water using zeolitic imidazole framework-8 (zif-8). Water Air Soil Pollut. 2015, 226. [CrossRef]

20. Wu, H.; Zhou, W.; Yildirim, T. Hydrogen storage in a prototypical zeolitic imidazolate framework-8. J. Am. Chem. Soc. 2007, 129, 5314-5315. [CrossRef] [PubMed]

21. Sun, C.Y.; Qin, C.; Wang, X.L.; Yang, G.S.; Shao, K.Z.; Lan, Y.Q.; Su, Z.M.; Huang, P.; Wang, C.G.; Wang, E.B. Zeolitic imidazolate framework-8 as efficient PH-sensitive drug delivery vehicle. Dalton Trans. 2012, 41, 6906-6909. [CrossRef] [PubMed]

22. Zhou, X.; Zhang, H.P.; Wang, G.Y.; Yao, Z.G.; Tang, Y.R.; Zheng, S.S. Zeolitic imidazolate framework as efficient heterogeneous catalyst for the synthesis of ethyl methyl carbonate. J. Mol. Catal. A Chem. 2013, 366, 43-47. [CrossRef]

23. Cui, J.; Feng, Y.; Lin, T.; Tan, Z.; Zhong, C.; Jia, S. Mesoporous metal-organic framework with well-defined cruciate flower-like morphology for enzyme immobilization. ACS Appl. Mater. Interfaces 2017, 9, 10587-10594. [CrossRef] [PubMed]

24. Kida, K.; Okita, M.; Fujita, K.; Tanaka, S.; Miyake, Y. Formation of high crystalline zif-8 in an aqueous solution. CrystEngComm 2013, 15, 1794. [CrossRef]

25. Amedi, H.R.; Aghajani, M. Aminosilane-functionalized zif-8/peba mixed matrix membrane for gas separation application. Microporous Mesoporous Mater. 2017, 247, 124-135. [CrossRef] 
26. Liang, K.; Ricco, R.; Doherty, C.M.; Styles, M.J.; Bell, S.; Kirby, N.; Mudie, S.; Haylock, D.; Hill, A.J.; Doonan, C.J.; et al. Biomimetic mineralization of metal-organic frameworks as protective coatings for biomacromolecules. Nat. Commun. 2015, 6, 7240. [CrossRef] [PubMed]

27. Ramimoghadam, D.; Hussein, M.Z.; Taufiq-Yap, Y.H. The effect of sodium dodecyl sulfate (SDS) and cetyltrimethylammonium bromide (CTAB) on the properties of Zno synthesized by hydrothermal method. Int. J. Mol. Sci. 2012, 13, 13275-13293. [CrossRef] [PubMed]

28. Kuan, I.C.; Lee, C.-C.; Tsai, B.-H.; Lee, S.-L.; Lee, W.-T.; Yu, C.-Y. Optimizing the production of biodiesel using lipase entrapped in biomimetic silica. Energies 2013, 6, 2052-2064. [CrossRef]

29. Su, F.; Li, G.; Zhang, H.; Yan, Y. Enhanced performance of rhizopus oryzae lipase immobilized on hydrophobic carriers and its application in biorefinery of rapeseed oil deodorizer distillate. BioEnergy Res. 2014, 7, 935-945. [CrossRef]

30. Jin, W.; Brennan, J.D. Properties and applications of proteins encapsulated within sol-gel derived materials. Anal. Chim. Acta 2002, 461,1-36. [CrossRef]

31. Tsai, H.C.; Doong, R.A. Preparation and characterization of urease-encapsulated biosensors in poly(vinyl alcohol)-modified silica sol-gel materials. Biosens. Bioelectron. 2007, 23, 66-73. [CrossRef] [PubMed]

32. Mateo, C.; Palomo, J.M.; Fernandez-Lorente, G.; Guisan, J.M.; Fernandez-Lafuente, R. Improvement of enzyme activity, stability and selectivity via immobilization techniques. Enzyme Microb. Technol. 2007, 40, 1451-1463. [CrossRef]

33. Kim, J.; Grate, J.W.; Wang, P. Nanobiocatalysis and its potential applications. Trends Biotechnol. 2008, 26, 639-646. [CrossRef] [PubMed]

34. Cauet, E.; Rooman, M.; Wintjens, R.; Lievin, J.; Biot, C. Histidine-aromatic interactions in proteins and protein-ligand complexes: Quantum chemical study of X-ray and model structures. J. Chem. Theory Comput. 2005, 1, 472-483. [CrossRef] [PubMed]

35. Khan, F.I.; Lan, D.; Durrani, R.; Huan, W.; Zhao, Z.; Wang, Y. The lid domain in lipases: Structural and functional determinant of enzymatic properties. Front. Bioeng. Biotechnol. 2017, 5, 16. [CrossRef] [PubMed]

36. Ji, Q.; Xiao, S.; He, B.; Liu, X. Purification and characterization of an organic solvent-tolerant lipase from Pseudomonas aeruginosa LX1 and its application for biodiesel production. J. Mol. Catal. B Enzym. 2010, 66, 264-269. [CrossRef]

37. Liu, Y.; Liu, T.; Wang, X.; Xu, L.; Yan, Y. Biodiesel synthesis catalyzed byburkholderia cenocepacialipase supported on macroporous resin nka in solvent-free and isooctane systems. Energy Fuels 2011, 25, 1206-1212. [CrossRef]

38. Lu, J.; Chen, Y.; Wang, F.; Tan, T. Effect of water on methanolysis of glycerol trioleate catalyzed by immobilized lipase Candida sp. 99-125 in organic solvent system. J. Mol. Catal. B Enzym. 2009, 56, 122-125. [CrossRef]

39. Li, Q.; Yan, Y. Production of biodiesel catalyzed by immobilized Pseudomonas cepacia lipase from sapium sebiferum oil in micro-aqueous phase. Appl. Energy 2010, 87, 3148-3154. [CrossRef]

40. Royon, D.; Daz, M.; Ellenrieder, G.; Locatelli, S. Enzymatic production of biodiesel from cotton seed oil using t-butanol as a solvent. Bioresour. Technol. 2007, 98, 648-653. [CrossRef] [PubMed]

41. Szczęsna Antczak, M.; Kubiak, A.; Antczak, T.; Bielecki, S. Enzymatic biodiesel synthesis-Key factors affecting efficiency of the process. Renew. Energy 2009, 34, 1185-1194. [CrossRef]

42. Kumari, A.; Mahapatra, P.; Garlapati, V.K.; Banerjee, R. Enzymatic transesterification of jatropha oil. Biotechnol. Biofuels 2009, 2, 1. [CrossRef] [PubMed]

43. Fan, Y.; Su, F.; Li, K.; Ke, C.; Yan, Y. Carbon nanotube filled with magnetic iron oxide and modified with polyamidoamine dendrimers for immobilizing lipase toward application in biodiesel production. Sci. Rep. 2017, 7, 45643. [CrossRef] [PubMed]

44. Andrade, T.A.; Errico, M.; Christensen, K.V. Influence of the reaction conditions on the enzyme catalyzed transesterification of castor oil: A possible step in biodiesel production. Bioresour. Technol. 2017, 243, 366-374. [CrossRef] [PubMed]

45. Yan, Y.; Li, X.; Wang, G.; Gui, X.; Li, G.; Su, F.; Wang, X.; Liu, T. Biotechnological preparation of biodiesel and its high-valued derivatives: A review. Appl. Energy 2014, 113, 1614-1631. [CrossRef]

46. Fan, Y.; Ke, C.; Su, F.; Li, K.; Yan, Y. Various types of lipases immobilized on dendrimer-functionalized magnetic nanocomposite and application in biodiesel preparation. Energy Fuels 2017, 31, 4372-4381. [CrossRef] 
47. Pan, S.; Liu, X.; Xie, Y.; Yi, Y.; Li, C.; Yan, Y.; Liu, Y. Esterification activity and conformation studies of Burkholderia cepacia lipase in conventional organic solvents, ionic liquids and their co-solvent mixture media. Bioresour. Technol. 2010, 101, 9822-9824. [CrossRef] [PubMed]

48. Liu, Y.; Chen, D.; Yan, Y.; Peng, C.; Xu, L. Biodiesel synthesis and conformation of lipase from Burkholderia cepacia in room temperature ionic liquids and organic solvents. Bioresour. Technol. 2011, 102, 10414-10418. [CrossRef] [PubMed]

49. Li, K.; Fan, Y.; He, Y.; Zeng, L.; Han, X.; Yan, Y. Burkholderia cepacia lipase immobilized on heterofunctional magnetic nanoparticles and its application in biodiesel synthesis. Sci. Rep. 2017, 7, 16473. [CrossRef] [PubMed]

50. Su, F.; Li, G.-L.; Fan, Y.-L.; Yan, Y.-J. Enhancing biodiesel production via a synergic effect between immobilized Rhizopus oryzae lipase and novozym 435. Fuel Process. Technol. 2015, 137, 298-304. [CrossRef]

2018 by the authors. Licensee MDPI, Basel, Switzerland. This article is an open access article distributed under the terms and conditions of the Creative Commons Attribution (CC BY) license (http:/ / creativecommons.org/licenses/by/4.0/). 